\title{
A Rapid and Sensitive Method for Dimethylsulphide Analysis in Brazilian Sugar Cane Sugar Spirits and Other Distilled Beverages
}

\author{
Daniel R. Cardoso, Luiz G. Andrade Sobrinho, Benedito S. Lima-Neto and Douglas W. Franco* \\ Instituto de Química de São Carlos, Universidade de São Paulo, CP 780, 13560-970 São Carlos - SP, Brazil
}

\begin{abstract}
O acoplamento do extrator por "purge and trap" com a cromatografia gasosa foi utilizado para quantificar o dimetilssulfeto em bebidas alcoólicas. Muito boa performance foi obtida usando-se uma coluna HP-FFAP e um detector seletivo de massas operando em modo SIM $(\mathrm{m} / \mathrm{z}, 62)$ : limite de detecção de $8 \times 10^{-9} \mathrm{~mol} \mathrm{~L}^{-1}$; boa repetibilidade e tempo total de análise de 25 minutos. O método foi aplicado em 60 amostras de bebidas alcoólicas (cachaça, tiquira, grapa, uísque, brandy, vodca, rum e uma tequila). As amostras de cachaças exibiram a maior concentração de dimetilssulfeto (mediana de $3.16 \times 10^{-4} \mathrm{~mol} \mathrm{~L}^{-1}$ ) seguidas pelas amostras de grapa (mediana de $1.45 \times 10^{-4} \mathrm{~mol} \mathrm{~L}^{-1}$ ). Não foi observada a presença de dimetilssulfeto nas amostras de rum analisadas.
\end{abstract}

\begin{abstract}
A purge and trap concentrator coupled to gas chromatography was used to quantify dimethylsulphide in distilled beverages. A very good performance was obtained using a HP-FFAP column and a mass selective detector operating in SIM mode $(\mathrm{m} / \mathrm{z}, 62)$ : detection limit $8 \times 10^{-9} \mathrm{~mol} \mathrm{~L}^{-1}$; good repeatability and total time of analysis 25 minutes. The method has been applied for sixty samples of alcoholic beverages (cachaças, tiquiras, grappas, whiskies, brandies, vodkas, rum and a tequila). The cachaças exhibit the highest content of dimethylsulphide (median $3.16 \times 10^{-4} \mathrm{~mol} \mathrm{~L}^{-1}$ ), followed by grappa (median $1.45 \mathrm{x}$ $\left.10^{-4} \mathrm{~mol} \mathrm{~L}^{-1}\right)$. The presence of dimethylsulphide was not observed in the samples of rum.
\end{abstract}

Keywords: cachaça, chromatography, purge and trap, dimethylsulphide, GC-MS

\section{Introduction}

Brazilian sugar cane spirit, also called "cachaça", is a distilled alcoholic beverage from fermented sugar cane juice. Although cachaça production is around $1.5-2 \times 10^{9}$ liters per year, only $2.6 \times 10^{6}$ liters are exported. Significant improvements can be obtained from knowledge of the cachaça chemical composition; however this subject has only been thoroughly investigated in the last decade. ${ }^{1-5}$

Flavor and aroma are the most important sensory characteristics of a beverage. The presence of sulphur compounds in beverages makes the sensorial profile worse as these compounds are known to be responsible for the so-called "off-flavors". 5 -9

Sulphur compounds in beverages exhibit different olfactory characteristics, depending on the position of the sulphur atom in the molecule, ${ }^{5}$ and probably originate from the degradation of sulphur-containing amino acids. ${ }^{5}$

Previous studies carried out in our laboratory indicated that dimethylsulphide (DMS) is the major volatile sulphur component in cachaça and can strongly influence the beverage sensory qualities. ${ }^{11}$

\footnotetext{
* e-mail: douglas@iqsc.usp.br
}

The reported analytical methods $\mathrm{s}^{5-9,12-15}$ for DMS determination, based on chromatographic analysis, are laborious, show a low detection limit, and are subject to interferences.

As part of our efforts aiming at improving Brazilian cane sugar spirit quality, we describe here a simple and rapid method for the quantitative analysis of DMS in cachaça and other alcoholic matrices, employing the purge and trap technique ${ }^{16}$ coupled to a gas chromatograph having a mass spectrometric detector (GC-MS). The following samples were analyzed: twenty-two cachaças, eight tiquiras (home made distilled beverage of beiju from manioc fermentation produced in Maranhão state, Brazil), eight whiskies, seven grappas, four rums, nine brandies, ten vodkas and one tequila.

\section{Experimental}

\section{Reagents}

The solvent (ethanol) was HPLC grade (Mallinckrodt). The 99\% DMS standard was obtained from Aldrich. Water which was previously distilled and purified by a Milli-Q system (Millipore). 


\section{Sampling}

To obtain representative sampling, commercial Brazilian cane sugar spirits were collected from selected areas (States in Brazil: $\mathrm{AL}=$ Alagoas, $\mathrm{CE}=$ Ceará, $\mathrm{MA}=$ Maranhão, MG = Minas Gerais, $\mathrm{PE}=$ Pernambuco, $\mathrm{SC}=$ Santa Catarina, SP = São Paulo), taking into account their tradition as producers. For comparison purposes, other alcoholic beverages were selected according to consumer acceptance and commercial relevance.

The analytical data reported in this paper are the average values obtained from analysis of three samplings of the same beverage:

Brazilian cane sugar spirit samples. Box 32 (SC), Caninha 21 (SP), Caninha 61 (SP), Capitão das Geraes (MG), Sta. Inês (SP), Delicate (SP), Espírito de Minas (MG), Gostosa (PB), Jequity (SP), Kariri com K (CE), Lua Nova (MG), Marimbondo (PB), Nabunda (SP), Pé-de-Serra (AL), Pirassununga 51 (SP), Pitú (PE), Sapupara Ouro (CE), Tiquara (SP), Velho Barreiro (SP), Villa Velha (SP), Villa Velha Carvalho (SP), Ypióca Prata (CE).

Tiquira samples. Tiquira I (MA), Tiquira II (MA), Tiquira III (MA), Tiquira IV (MA), Tiquira V (MA), Tiquira IX (MA), Tiquira XIV (MA), Tiquira XV (MA).

Whiskey samples. Alambik (Brazil), Early Times (USA), Jim Beam (USA), Passport (Scotland), Crown Seagram's Seven (USA), Glendfiddich (Scotland), Logan (Scotland), Wild Turkey (USA).

Grappa samples. Grappa Chambave Muscat (Italy), Grappa di Malvasia di Casorzo (Italy), Grappa di Teroldego (Italy), Grappa Eugenia (Italy), Grappa Florianópolis (SC, Brazil), Grappa Pisoni (Italy), Siborna Grappa (Italy).

Rum samples. Montilla (SP), Myer's (Jamaica), Rhum Agricole Sain Jaimes Martinica (France), Ron Aniversario (Venezuela).

Brandy samples. Äalborg Vinbärs (Denmark), Brandy Peinado (Spain), Cacique Guaro (Costa Rica), Domeq (Brazil), Domus (Brazil), Dreher (Brazil), Gran Duque D’Alba (Spain), Natu Nobilis (Brazil), Presidente (Brazil).

Vodka samples. Baikal (Brazil), Balalaika (Brazil), Komaroff (Brazil), Orloff (Brazil), Smirnoff (Brazil), Stolichnaya (Russia), Dofrahb (Russia), Wyborowa (Russia), Zubrowka (Russia).

Tequila sample. Cuervo Especial (Mexico).

\section{Equipment}

Determinations of dimethylsulphide was carried out in a purge and trap concentrator (OI ANALYTICAL, model 4560) using high purity helium (99.999\%), coupled with a gas chromatograph (SHIMADZU, model GC17A) equipped with a mass selective detector (SHIMADZU, model GCMS-QP5050A) using $70 \mathrm{eV}$ electron impact as the ionization mode. Separation was achieved in a column packed with esterified polyethylene glycol (HP-FFAP, $50 \mathrm{~m}$ x $0.2 \mathrm{~mm}$ x $0.3 \mu \mathrm{m}$; Hewlett Packard), three other capillary columns were tested: DB-WAX $(50 \mathrm{~m} \times 0.20 \mathrm{~mm} \times 0.3 \mathrm{~mm}$; J\&W Scientific), DB-1 (60 m x 0.25 mm x $0.3 \mu \mathrm{m} ; \mathrm{J} \& \mathrm{~W}$ Scientific) and DB-5 (60 m x $0.25 \mathrm{~mm} \times 0.3 \mu \mathrm{m} ; \mathrm{J} \& \mathrm{~W}$ Scientific). Compounds in the purge gas were adsorbed on a Tenax ${ }^{\circledR}$ chemical trap (OI ANALYTICAL) using a water management control module to minimize co-recovery of water from liquid samples.

\section{Methodology}

Aliquots of six milliliters of each sample were injected in the purge and trap concentrator and purged for $5 \mathrm{~min}$ at a flow rate of $45 \mathrm{~mL} \mathrm{~min}^{-1}$. The trap temperature was set at $20{ }^{\circ} \mathrm{C}$. The trap was then flash-heated to $180{ }^{\circ} \mathrm{C}$ for $2 \mathrm{~min}$ to desorb the volatile compounds, which were automatically injected directly into the GC-MS equipment.

The gas chromatograph was operated in the on column injection mode. The column temperature was set at $60{ }^{\circ} \mathrm{C}$ for 5 min after which it was raised to $200{ }^{\circ} \mathrm{C}$ at a rate of $10{ }^{\circ} \mathrm{C} \mathrm{min}{ }^{-1}$. Helium at a flow rate $1 \mathrm{~mL} \mathrm{~min}^{-1}$ was used as the carrier gas. The mass spectrometer detector was operated in the single ion monitoring (SIM) mode $(\mathrm{m} / \mathrm{z}$ 62). The temperatures of the injector and interface were set at $100{ }^{\circ} \mathrm{C}$ and $200{ }^{\circ} \mathrm{C}$, respectively.

The chemical trap was heated for $10 \mathrm{~min}$ at $200^{\circ} \mathrm{C}$ immediately before each analysis to remove residual compounds from previous analyses. Blank runs were included between each analysis to confirm that the residual compounds had been completely removed after heating.

\section{Quantitative analysis}

Standard solutions of DMS were obtained by suitable dilutions of a stock solution (7.08 x 10-3 $\mathrm{mol} \mathrm{L}^{-1} 60: 40 \mathrm{v} / \mathrm{v}$ water-ethanol solution). The calibration curve was determined over the $0-1.61 \times 1 \times 0^{-6} \mathrm{~mol} \mathrm{~L}^{-1}$ concentration range by plotting the peak area versus DMS concentration. The correlation coefficients were close to unity. The standard solutions and the calibration curves were prepared and used on the same day. When necessary the samples were diluted before analysis.

\section{Results and Discussion}

Several temperature programs and four capillary columns were tested: HP-FFAP, DB-WAX, DB-1, and DB- 
5. The HP-FFAP column exhibited the best performance without co-elution problems, as observed with the other capillary columns tested.

The mass fragmentation pattern of DMS is depicted in Figure 1 . The base peak at $\mathrm{m} / \mathrm{z} 47$ corresponds to the ion $\left[\mathrm{CH}_{3} \mathrm{~S}^{+}\right]$. The analyte displays an intense molecular ion at $\mathrm{m} / \mathrm{z} 62$ in the $70 \mathrm{eV}$ electron impact mass spectrum. This molecular ion was used for both qualitative and quantitative analysis, since the $\left[\mathrm{CH}_{3} \mathrm{~S}^{+}\right]$ion at $\mathrm{m} / z 47$ is subject to interference. The molecular ion at $\mathrm{m} / \mathrm{z} 62$ provides high selectivity and sensitivity and thus was chosen for quantitative analysis.

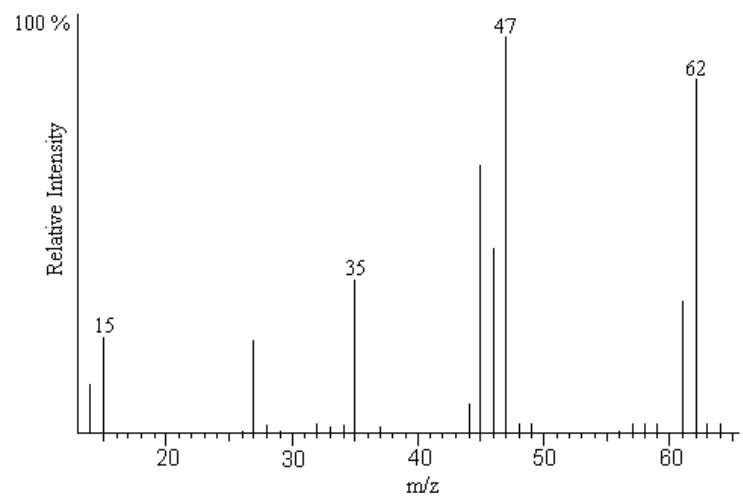

Figure 1. $70 \mathrm{eV}$ electron impact mass spectrum of DMS.
The identity of DMS from several samples was confirmed by comparing the retention times and mass fragmentation patterns with that of the authentic compound.

Repeatability of DMS analysis was determined as a relative standard deviation (RSD), as previous described. ${ }^{17}$ The low RSD values ( $2 \%$ ) confirmed the high precision of the determination of these compounds by the purge and trap technique.

The results of experimental quantification data for DMS in different distilled alcoholic beverages are shown in Table 1.

Using the method outlined here, it was not possible to detect the presence of DMS in the rum, tequila and vodka samples. Only one sample of tiquira and one of brandy showed DMS present in the concentration range for which the method is applicable. In three whiskey samples DMS was detected in concentrations similar to those already reported in literature. ${ }^{18}$ Grappa and whiskey samples presented similar ranges of concentration for DMS, with one exception (grappa \# 4) that exhibited a DMS level similar to those observed in cachaça.

The data collected in the Table 1 shows a high variation of the DMS concentration in the same type of beverage. In general, the range of concentration is between the detection

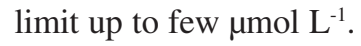

Table 1. Quantitative analysis of dimethylsulphide in alcoholic beverages ${ }^{a}$

\begin{tabular}{|c|c|c|c|c|c|c|c|c|c|}
\hline Cachaças & $\mathrm{DMS}^{\mathrm{b}}$ & Grappa & $\mathrm{DMS}^{\mathrm{c}}$ & Whiskies & $\mathrm{DMS}^{\mathrm{c}}$ & Brandies & $\mathrm{DMS}^{\mathrm{c}}$ & Tiquiras & $\mathrm{DMS}^{\mathrm{c}}$ \\
\hline 1 & 2.11 & 1 & 59.6 & 1 & $<$ LOD & 1 & $<$ LOD & 1 & $<$ LOD \\
\hline 2 & 12.4 & 2 & 6.44 & 2 & $<$ LOD & 2 & $<$ LOD & 2 & $<\mathrm{LOD}$ \\
\hline 3 & 7.34 & 3 & 14.5 & 3 & 43.5 & 3 & $<$ LOD & 3 & $<\mathrm{LOD}$ \\
\hline 4 & 2.21 & 4 & 340 & 4 & $<\mathrm{LOD}$ & 4 & 8.05 & 4 & $<\mathrm{LOD}$ \\
\hline 5 & 4.28 & 5 & 41.9 & 5 & $<$ LOD & MEDIAN & 0 & 5 & $<\mathrm{LOD}$ \\
\hline 6 & 1.87 & 6 & 1.61 & 6 & $<$ LOD & & & 6 & $<\mathrm{LOD}$ \\
\hline 7 & 7.53 & 7 & $<$ LOD & 7 & 20.9 & & & 7 & $<\mathrm{LOD}$ \\
\hline 8 & 220 & MEDIAN & 1.45 & 8 & 46.7 & & & 8 & 9.66 \\
\hline 9 & 1.34 & & & MEDIAN & 0 & & & MEDIAN & 0 \\
\hline 10 & 2.83 & & & & & & & & \\
\hline 11 & 2.04 & & & & & & & & \\
\hline 12 & 11.1 & & & & & & & & \\
\hline 13 & 39.4 & & & & & & & & \\
\hline 14 & 1.38 & & & & & & & & \\
\hline 15 & 2.22 & & & & & & & & \\
\hline 16 & 3.46 & & & & & & & & \\
\hline 17 & 2.48 & & & & & & & & \\
\hline 18 & 16.9 & & & & & & & & \\
\hline 19 & 7.63 & & & & & & & & \\
\hline 20 & 1.69 & & & & & & & & \\
\hline 21 & 0.85 & & & & & & & & \\
\hline 22 & 1.80 & & & & & & & & \\
\hline MEDIAN & 3.16 & & & & & & & & \\
\hline
\end{tabular}




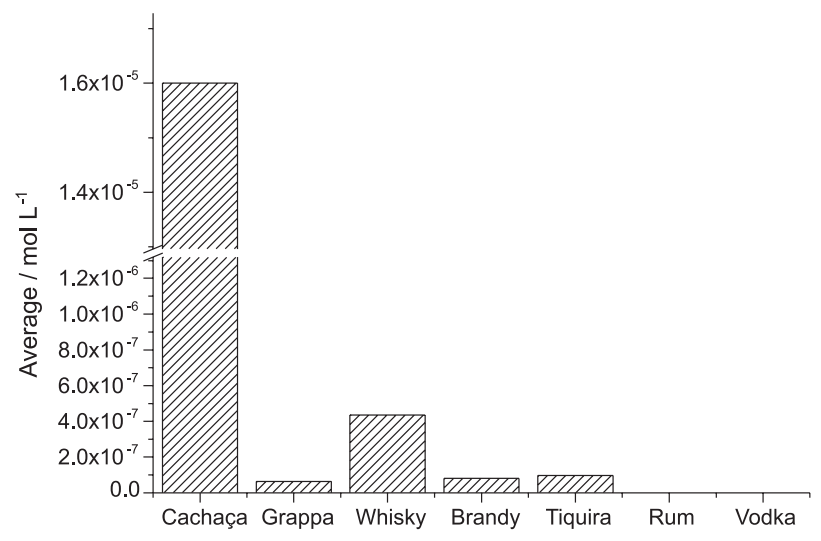

Figure 2. Histogram indicating the average contents of DMS in the beverages under investigation in this work.

As observed in Figure 2, the highest levels of DMS were found in the cachaça samples. It is very interesting to note that despite rum and cachaça being produced from sugar cane, the highest value of DMS were found in cachaça. Homemade cachaças produced in pot-stills exhibit higher DMS content than the industrial ones. Pot stills and columns (even the so called inox columns) have copper in their composition due to the well know properties of this metal to improve the sensory quality of beverages. Generally one could suppose that industrial cachaças were produced with better technologies than homemade ones and that this will be the reason for the observed DMS contents. This is not always true. Tiquira, despite its being produced with poorer quality control than rum and cachaça, exhibits low levels of DMS comparable to other international spirits.

Despite some differences in the design and configuration of the still, the use of copper metal in building the equipment, with the purpose of reducing the DMS content in distilled beverages ${ }^{19}$ is a worldwide practice and together with the distillation procedure can not by themselves explain the differences observed among cachaça, rum and tiquira DMS contents.

Probably, the differences in the sulphur compounds content of the raw material used in the fermentation stage of cachaça (fresh sugar cane juice), rum (molasses) and tiquira (beiju from manioc) and as well as the differences in the activities of the microbial population developed in the fermentation process would account for the observed results. This subject is currently under investigation in our laboratory.

The relevance of DMS on the cachaça's sensory profile can be easily evaluated by smelling a recently opened bottle. The characteristic cabbage DMS "off-flavor" is easily identified if it is present in a concentration higher than $8 \times 10^{-7} \mathrm{~mol} \mathrm{~L}^{-1} .{ }^{20}$ Chromatographic measurements in an open non-aged cachaça bottle, kept at room temperature $\left(25^{\circ} \mathrm{C} \pm 3\right.$ ) over two weeks, show less than $15 \%$ decrease in the DMS content. This fact at first view is surprising considering that DMS has a b.p. $=38^{\circ} \mathrm{C}$. Probably, in the cachaça's composition there are substances besides ethanol that interact with DMS increasing its solubility in this medium. The use of air or oxygen as a blanch gas, to eliminate DMS is not recommended since other volatile compounds will also be lost, consequently weakening the beverage's bouquet and aroma. Therefore, efforts should be carried out to eliminate or reduce the DMS content of cachaça. As pointed out above, the use of copper in the ascendant part of the pot-still and a double distillation process would be practical ways to accomplish this goal. ${ }^{19}$

\section{Conclusion}

The procedure described in the present study was shown to be rapid (25 min), detection limit of $8 \times 10^{-9} \mathrm{~mol} \mathrm{~L}^{-1}$, simple (does not require sample treatment) and also exhibits good precision (98\%). Therefore, it is quite suitable for quality control in routine analysis, in contrast to the usual methods described in the literature. The high concentrations of DMS found in some beverages indicate that production processing should be monitored more carefully. New studies on process development must be conducted to improve the flavor quality of the Brazilian national beverage.

\section{Acknowledgement}

The authors thank FAPESP and CAPES for financial support.

\section{References}

1. Boscolo, M.; Bezerra, C. W. B.; Cardoso, D. R.; Lima-Neto, B. S.; Franco, D. W.; J. Braz. Chem. Soc. 2000, 11, 86.

2. Nascimento, R. F.; Cardoso, D. R.; Lima-Neto; B. S.; Franco, D. W.; Chromatographia 1998, 48, 751.

3. Nascimento, R. F.; Cardoso, D. R.; De Keukeleire, D.; LimaNeto, B. S.; Franco, D. W.; J. Agric. Food Chem. 2000, 48, 6070 .

4. Aresta, M.; Boscolo, M.; Franco, D. W.; J. Agric. Food Chem. 2001, 49, 2819.

5. Lima-Neto, B.S.; Bezerra, C.W.; Polastro, L.R.; Campos, P.; Nascimento, R.F.; Furya, S.M.B.; Franco, D.W; Quim. Nova 1994, 17, 20.

6. Mestres, M.; Busto, O.; Guasch, J.; J. Chromatogr. A 2000, 881, 569.

7. Mestres, M.; Martí, M.P.; Busto, O.; Guasch, J.; J. Chromatogr. A 2000, 881, 583. 
8. Hill, P.G.; Smith, R.M.; J. Chromatogr. A 2000, 872, 203.

9. Leppänen, O.A.; Denslow, J.; Ronkaien, P.P.; J Agric. Food Chem 1980, 28, 359.

10. Nedjma, M.; Maujean, A.; J. Chromatogr. A 1995, 704, 495.

11. Nascimento, R.F.; PhD Thesis, Universidade de São Paulo, Brazil, 1998.

12. Haberhauer-Troyer, C.; Rosenberg, E.; Grasserbauer, M.; J. Chromatogr. A 1999, 848, 305.

13. Inomata, Y.; Matsunaga, K.; Murai, Y.; Osada, K.; Iwasaka, Y.; J. Chromatogr. A 1999, 864, 111.

14. Mestres, M.; Martí, M.P.; Busto, O.; Guasch, J.; J. Chromatogr. A 1999, 849, 293.

15. Ojala, M.; Ketola, R.; Mansikka, T.; Kotiaho, T.; Kostiainen, R.; J. High Resolut. Chromatogr. 1997, 20, 165.

16. Ioffe, B.V.; Itenberg, A.G.; Head-Space Analysis and Related Methods in Gas Chromatography, John Wiley: New York, 1984.
17. Chasin, A.A.M.; Nascimento, E.S.; Ribeiro-Neto, L.M.; Siqueira, M.E.P.B.; Andraus, M.H.; Salvadori, M.C.; Fernícola, N.A.G.; Gorni, R.; Salcedo, S.; Rev. Bras. Toxicol 1998, 11, 1.

18. Leppänen, O.A.; Denslow, J.; Ronkainen, P.A.; J. Inst. Brew. 1979, 85, 350.

19. Cardoso, D.R.; Nascimento, R.F.; Lima-Neto, B.S.; Franco, D.W.; Quim. Nova 2003, 26, 165.

20. Nascimento, R.F.; Cardoso, D.R.; Lima Neto, Benedito S.; Franco, D. W.; Farias, J.B.; Quim.Nova, 1998, 21, 735.

21. Mestres, M; Busto, O.; Guash, J.; J. Chromatogr. A 2000, 881, 569.

Received: February 6, 2003

Published on the web: March 30, 2004

FAPESP helped in meeting the publication costs of this article. 